\title{
Social capital and violence in the United States, 1974-1993
}

\author{
Sandro Galea ${ }^{\mathrm{a}, \mathrm{b}, *}$, Adam Karpatia ${ }^{\mathrm{a}, \mathrm{c}}$, Bruce Kennedy ${ }^{\mathrm{a}}$ \\ ${ }^{a}$ Department of Health and Social Behavior, Harvard School of Public Health, 718 Huntington Avenue, Boston, MA 02115, USA \\ ${ }^{\mathrm{b}}$ Center for Urban Epidemiologic Studies, New York Academy of Medicine, 1216 th Avenue, Room 556, New York, NY 10029, USA \\ ${ }^{\mathrm{c}}$ Epidemiology Program Office, Centers for Disease Control and Prevention, Atlanta, GA 30333, USA
}

\begin{abstract}
Social capital is a characteristic of communities. Cross-sectional studies have shown that social capital is inversely associated with homicide and violent crime. We hypothesized that variations in social capital in US states over time can predict variations in regional homicide mortality both across and within time periods. We analyzed serial crosssectional data for measures of social capital and age-adjusted homicide rates between 1974 and 1993. We used perception of social trust and per capita membership in voluntary associations, obtained from responses to the General Social Surveys, as the principal measures of social capital. We controlled for potential confounding by mean levels of income, urbanization, and region. Measures of perceived trust were strongly inversely correlated with homicide rates in an aggregate cross-sectional analysis $(r=-0.51, p<0.001)$ and also within each time period. Social capital was an independent predictor of rates of violence when controlling for income, region, and urbanization $(p<0.001)$. Homicide rates also predicted levels of social capital in adjusted models $(p<0.001)$. To investigate directionality of this relationship we developed Markov transition matrices that described the change in the states' levels of social capital and homicide across time intervals. Analysis of the transitional probabilities confirmed that a simple unidirectional association between social capital and violence was not sufficient to describe this association. There is likely an impact of violence on levels of perceived trust in communities that complements the hypothesized effect of social capital on homicide. We conclude that the relationship between social capital and violence over time is non-linear and dynamic. More complex analytic models describing the relationship between violence and ecological social determinants need to be considered. (C) 2002 Elsevier Science Ltd. All rights reserved.
\end{abstract}

Keywords: Social capital; Homicide; Crime; Violence; Social determinants; United States

\section{Introduction}

Homicide remains one of the leading causes of premature mortality in the US population and is the leading cause of death among African American young adults (Singh, Kochanek, \& MacDorman, 1996). Research on community characteristics associated with violent crime dates back to more than a century (Quetelet, 1842). Researchers exploring the sociological

*Corresponding author. Center for Urban Epidemiologic Studies, New York Academy of Medicine, 1216 5th Avenue, Room 556, New York, NY 10029, USA. Tel.: 212-822-7378; fax: 212-876-6220.

E-mail address: sgalea@nyam.org (S. Galea). and psychological roots of violence have identified individual and community-level characteristics that are associated with high levels of homicide and other violent crimes (Land, McCall, \& Cohen, 1990). Individual-level risk factors for violence include mental illness (e.g., personality disorders) (Johnson et al., 2000), psychological factors (e.g., aggression) (Klevens, Bayón, \& Sierra, 2000), and drug use (Goldstein, 1998).

At the community level, theoretical and empirical explanations for differential homicide rates have emerged from different disciplines suggesting that multiple pathways lead to violence (Dahlberg \& Potter, 2001). The "subculture of violence" hypothesis, referring to a value system that reinforces violent behavior, was first postulated to explain the high violence rates observed in 
the southern states (Wolfgang \& Ferracutti, 1967; Land et al., 1990). Subsequent theorists applied the subculture of violence hypothesis to urban areas, particularly to explain the disproportionately elevated crime rates in large metropolitan areas (Silberman, 1978). A competing theoretical framework, arising primarily out of studies of urbanization in Chicago, posited that large, dense, urban areas produce superficial human relations that in turn increase inter-individual conflict and necessitate increased formal regulation and control. This results in social disorganization, accompanied by poverty and selective population mobility away from urban areas. These developments lead to weakening of social control which permits the rise of criminal subcultures that increase rates of violence (Shaw \& McKay, 1942). Recent multilevel studies have confirmed parts of this theory showing that high levels of homicide are associated both with population emigration (Morenoff \& Sampson, 1997) and with characteristics of the social environment (e.g., poverty) (Cunradi, Caetano, Clark, \& Schafer, 2000). Although the predominant focus of this research has been on residential areas within cities, recent interest in contextual determinants of social behavior has also led to an interest in aggregate county and state-level factors that affect violence across these areas (Kawachi, Kennedy, \& Wilkinson, 1999).

One such contextual factor that has been recently explored in relation to violence is social capital. The term "social capital" attempts to capture key elements of community organization. While different authors have ascribed various meanings to the concept of social capital, it is generally defined by its principal theorists as the features of social organizations that facilitate collective action for mutual benefit (Coleman, 1990; Putnam, 1993). Social capital is both relational, i.e., encompassing benefits that individuals secure through membership in social structures, and material, i.e., including the resources to which an individual has access through her/his membership in a group (Hawe \& Schiell, 2000). The central aspect of social capital is trust which establishes a social network of reciprocity and social exchange that can be drawn upon by community members.

Social capital is an ecologic variable, a contextual feature of communities. Its relation to population, well being has been examined in cross-sectional studies of state-level data. These studies have demonstrated an inverse association between homicide rates and levels of social capital in US states, even after controlling for confounding by several state-level factors such as poverty levels and availability of firearms (Kennedy, Kawachi, Prothrow-Stith, Lochner, \& Gupta, 1998). A multilevel study at the neighborhood level of Chicago neighborhoods demonstrated an association between "collective efficacy" (a related concept that incorporates elements of social trust) and violence, after controlling for other neighborhood-level and individual-level risks (Sampson, Raudenbush, \& Earls, 1997). The relation between social capital and violence at the state level likely reflects the theoretical processes noted above. It is generally hypothesized that communities with low social capital are not effective in exercising informal social control and establishing norms that reduce violence (Sampson \& Wilson, 1995). This leads to increasing violence in communities with low social capital.

Implicit in the research that has demonstrated an association between social capital and violence is the suggestion that changing social capital can affect violence rates. Most studies of social capital and violence published thus far are based on cross-sectional data and have used regression models to identify associations (Kennedy et al., 1998). Multivariable regression models explicitly define the direction of the relation under study; usually variability in social factors is modeled as predicting variability in an outcome, such as violence. Cross-sectional data however allow only a limited range of inferences about this relationship. Observation of an association at any given time represents the product of a single analytic window that may or may not be representative of the relationship over time. Current conceptualization of the relation between social capital and violence suggest that there exist non-linear components to this association (Kawachi, 1999). That is, as social disorganization promotes violence, so could violence erode social organization. While this has been discussed theoretically, large-scale experiments to test the direction of the social capital-violence association are impossible to conduct.

We used a mixed ecological study design to explore the relation between social capital and violence over time (Morgenstern, 1995). We carried out serial crosssectional analyses of US state-level data for social capital and violence between 1974 and 1993. We fit regression models that describe both a relation where social capital predicts violence and a relation where violence predicts social capital. We complemented regression modeling with direct analysis of how states transition between levels of social capital and violence. We hypothesized, a priori, that variations in social capital at the US state level over time can predict variations in regional homicide mortality both across and within time periods.

\section{Methods}

\section{Measurement of social capital in US states}

Social capital has been commonly represented by the degree of citizen involvement in their communities and by levels of trust among community members. Follow- 
ing Putnam (1993) and Kawachi, Kennedy, Lochner, and Prothrow-Stith (1997), we used data from the General Social Surveys (GSSs), conducted by the National Opinion Research Center, to estimate stateto-state variations in levels of mutual trust and group membership. The GSS is a nationally representative telephone survey of English-speaking adults that has been conducted serially since the 1970s.

For this study, we analyzed pooled data for each of five periods (1974-1977, 1978-1981, 1982-1985, 19861989, and 1990-1993) for each US state. The number of respondents for each period ranged from 2277 in the 1978-1981 time period to 5321 from 1986-1989. Since the GSS is a nationally representative survey, the least populous states are not sampled in some years. We eliminated states that were not represented in any of the survey years, leaving 32 states in our study (Alabama, Arizona, Arkansas, California, Colorado, Connecticut, Florida, Georgia, Illinois, Indiana, Iowa, Kansas, Louisiana, Maryland, Massachusetts, Michigan, Minnesota, Missouri, New Jersey, New York, North Carolina, Ohio, Oklahoma, Oregon, Pennsylvania, South Carolina, Tennessee, Texas, Virginia, Washington, West Virginia, and Wisconsin).

We used three measures that have previously been used as proxies for mutual trust. They were: (i) "Do you think most people would try to take advantage of you if they got a chance, or would they try to be fair?" (perceived fairness); (ii) "Generally speaking, would you say that most people can be trusted or that you can't be too careful in dealing with people?" (perceived trust); and (iii) "Would you say that most of the time people try to be helpful, or are they mostly looking out for themselves?" (perceived helpfulness). For the purposes of this analysis, we used the proportion of respondents answering "Yes" to each question as the level for that indicator. All negative or equivocal responses were considered not indicative of perceived mutual trust, helpfulness or fairness. The results were pooled and averaged for each of the five periods.

The GSS also asks for the number of voluntary civic associations to which persons belong. This is asked of all persons for each of 14 associations (fraternal group, service group, veteran group, youth group, nationality group, literary or art group, church group, political club, sports club, labor union, professional society, school fraternity, school service or other). We considered respondents who belonged to at least one of these associations to be positive on the measure of association membership.

All responses to the GSS were weighted to account for the fact that the survey is designed to generate representative national and regional, but not state-level, data. We applied weights to the responses after the methods described in Kawachi et al. (1997). We used post-stratification weights based on the demographic distribution of age, race, and educational attainment of survey respondents. These weights were calculated as follows: $w_{i, j, k, l}=P_{i, j, k, l} / p_{i, j, k, l}$, where $w_{i, j, k, l}$ is the poststratification weight for the survey respondent residing in the $i$ th state and being of the $j$ th age group, $k$ th race and $l$ th level of educational attainment; $P_{i, j, k, l}$ is the proportion of persons with these characteristics residing in the $i$ th state (from the $1990 \mathrm{US}$ census) and $p_{i, j, k, l}$ is the corresponding proportion of such respondents in the GSS.

\section{Measurement of homicide mortality across US states}

We used mortality from homicide as an objective measure of violence in society, and obtained data from the National Center for Health Statistics Compressed Mortality File. We used age-adjusted mortality rates for each state (1990 US population standard) for each of the years 1974-1993 (International Classification of Diseases, 9th Edition ICD-9 codes for homicideE965-E965.4). All mortality rates were directly age-standardized to the 1990 US population and expressed as number of deaths per 100,000 persons. All rates were averaged over each of the five time intervals.

\section{Measurement of income and urbanization across US states}

We considered potential confounding of the relationship between social capital and violence by three ecologic variables: region, average income, and urbanization. These variables were among those identified as predictors of area-level homicide rates in a recent analysis across US health service areas (Cubbin, Williams Pickle, \& Fingerhut, 2000). Standard US Census coding for region was employed (New England, mid-Atlantic, East-North Central, West-North Central, South Atlantic, East-South Central, West-South Central, Mountain, Pacific). We obtained average income for each state for each of the years under investigation from the US Department of Commerce, Bureau of Economic Affairs. Urbanization was calculated as a percentage of each state's population in 1990 living in urban areas (1990 US Census Population and Housing Summary Tape File 3A). We pooled and averaged yearly data on potential confounders for each of the five periods.

\section{Data analysis}

We carried out six different analyses. First we used simple correlations and scatterplots to determine the correlations among the different measures of social capital collected and to explore the cross-sectional, and longitudinal relations between the variables of interest. 
Second, we used ordinary least-squares linear regression modeling, controlling for potential confounders, to describe the relation between social capital indicators and homicide mortality. Third, we modeled the data using generalized estimating equations (using an identity link function) to account for the potentially correlated nature of repeated measures for each of the states over time. Fourth, we constructed change models, in which the key variables were the difference in homicide and social capital mortality rates from one time period to the next. Fifth, to explore the potential delayed associations between predictors and outcome, we created transitional (Markov) logistic models as described by Diggle, Liang, and Zeger (1995). Mean values of homicide rates and trust were used to dichotomize the homicide rates and trust variable for the logistic analysis. Transitional models were in the form of $E\left(Y_{i j} \mid Y_{i, j-1}\right)=\alpha+X_{i j} \beta+$ $Y_{i j-1} \beta$ whereby the conditional distribution of each outcome variable was expressed as an explicit function of its past value and relevant covariates (Diggle et al., 1995). All models were fit first using homicide as dependent variable and social capital as independent variable and second using social capital as dependent variable and homicide as independent variable. All analyses were carried out using SAS-7 (Cary, NC) and S-Plus software.

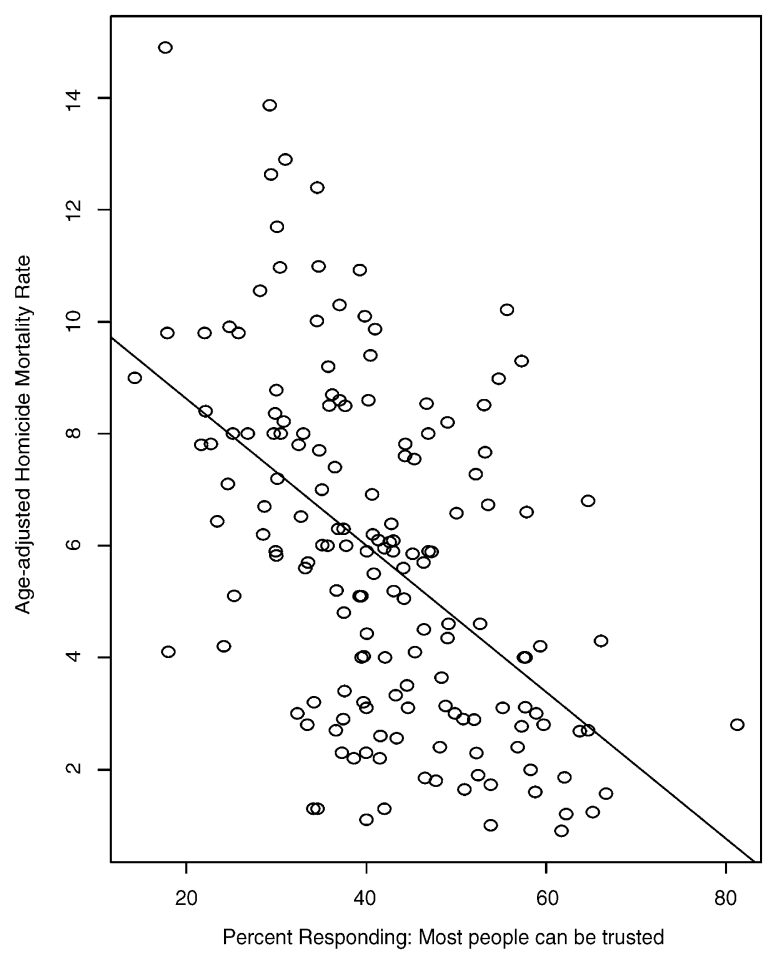

Sixth, we used transitional state analysis to further characterize the relation between social capital and violence. This technique does not involve the unidirectional assumptions inherent in the regression models (Perry, Lavori, \& Hoke, 1987). We created four distinct categories based on each US state's level of perceived trust and homicide (High Social Capital/High Violence, High Social Capital/Low Violence, Low Social Capital/High Violence, Low Social Capital/Low Violence), dichotomized by mean levels. We attributed each US state to one category for each time period. We then traced the movement of each US state between categories across time periods and calculated transition probabilities that described the likelihood of progression for a state from one category to another over time.

\section{Results}

\section{Description of data}

Mean homicide mortality for the 32 states during the time period 1974-1993 was 5.8 deaths per 100,000 persons (Standard Deviation $(\mathrm{SD})=3.0$ ); mean percent of respondents answering "Yes" on the social capital

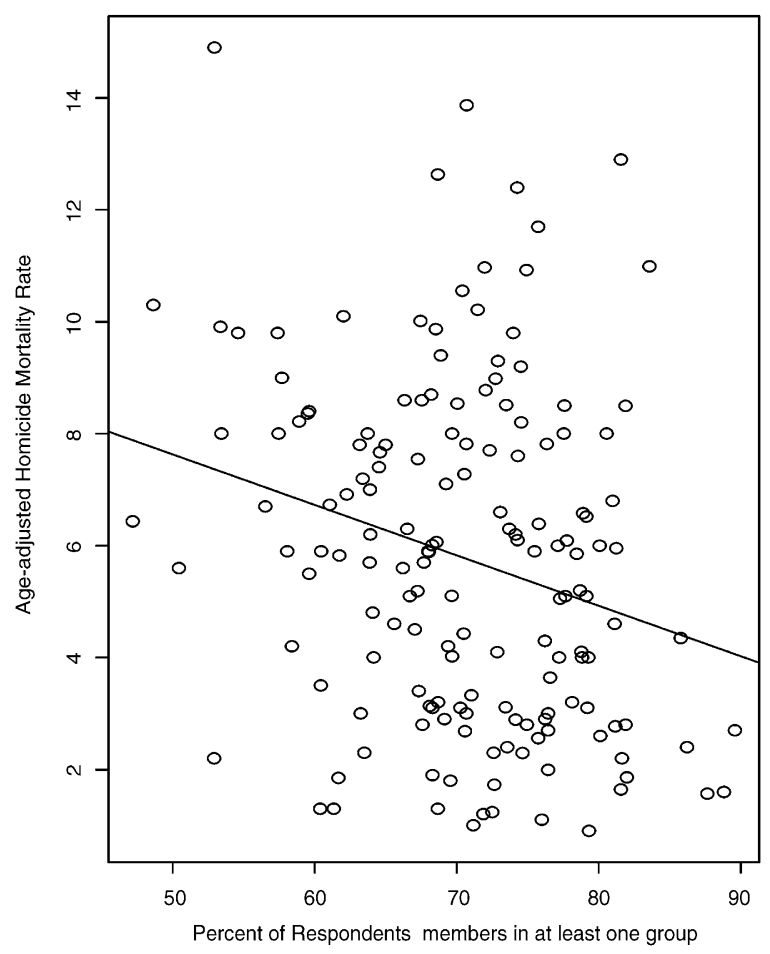

Fig. 1. Homicide rates (per 100,000 population) and social capital across 32 US states, aggregated from 1974 to $1993(n=160)$ (Pearson's correlation coefficient for trust and homicide $=-0.51(p<0.0001)$ and for membership and homicide $=-0.23(p=0.002))$. 
Table 1

Summary of social capital and violence measures across 32 US states, 1974-1993

\begin{tabular}{llr}
\hline Social capital measure & Mean percent responding "yes" & Standard deviation \\
\hline Trust $^{\mathrm{a}}$ bairness & 41.7 & 11.8 \\
Helpfulness $^{\mathrm{c}}$ & 60.6 & 10.6 \\
Membership $^{\mathrm{d}}$ & 52.8 & 9.8 \\
& 70.5 & 8.3 \\
\hline Violence measure & & Standard deviation \\
\hline Homicide & Mean rate across states (per 100,000 persons) & 3.0 \\
\hline
\end{tabular}

\footnotetext{
${ }^{a}$ Percent of respondents who responded affirmatively to "Generally speaking, would you say that most people can be trusted or that you can't be too careful in dealing with people?".

${ }^{\mathrm{b}}$ Percent of respondents who responded affirmatively to "Do you think most people would try to take advantage of you if they got a chance, or would they try to be fair?".

${ }^{\mathrm{c}}$ Percent of respondents who responded affirmatively to "Would you say that most of the time people try to be helpful, or are they mostly looking out for themselves?'.

${ }^{\mathrm{d}}$ Percent of respondents who belonged to at least one of 14 voluntary civic associations.
}

questions ranged from $41.7(\mathrm{SD}=11.8)$ for trust to 70.5 $(\mathrm{SD}=8.3)$ for membership (Table 1).

\section{Correlations among different measures of social capital}

The four measures of social capital were fairness, helpfulness, trust, and membership. Table 2 shows the correlations between these variables, pooled over all five time-periods. Correlations between measures of helpfulness, fairness, and trust were high, (Pearson correlation coefficients from $0.65-0.79$; all $p<0.0001$ ). These findings were consistent when each time period was analyzed separately. We confined our subsequent analyses to the measure of perceived trust. The pooled 1974-1993 percentage of positive responses to the trust measure followed an approximate Gaussian distribution and exhibited a wider range than did the measures of fairness and helpfulness, providing a better opportunity to explore the variability within perceptions of mutual trust across US states and across time periods.

The measure of membership was not as highly correlated with the other social capital indicators (Pearson correlation coefficients 0.27-0.45). We considered voluntary association membership separately from the measure of perceived trust in all analyses.

\section{Cross-sectional correlations between social capital measures and homicide mortality over time}

Inverse correlations between perceived trust and homicide rates were present and significant $(r=-0.51$, $p<0.0001$ ) when pooled across time periods (Fig. 1). We conducted separate analyses within each of the five timeperiods and found these relationships to be statistically
Table 2

Correlations between General Social Surveys' measures of social capital: Trust, helpfulness, fairness, and membership, across 32 US states, 1974-1993

\begin{tabular}{|c|c|c|c|}
\hline & Membership ${ }^{\mathrm{e}}$ & Trust & Fairness \\
\hline Trust $^{\mathrm{b}}$ & $\begin{array}{c}0.45^{\mathrm{a}} \\
(<0.0001)\end{array}$ & & \\
\hline Fairness ${ }^{\mathrm{c}}$ & $\begin{array}{c}0.39 \\
(<0.0001)\end{array}$ & $\begin{array}{c}0.70 \\
(<0.0001)\end{array}$ & \\
\hline Helpfulness ${ }^{\mathrm{d}}$ & $\begin{array}{l}0.27 \\
(0.0006)\end{array}$ & $\begin{array}{c}0.65 \\
(<0.0001)\end{array}$ & $\begin{array}{c}0.70 \\
(<0.0001)\end{array}$ \\
\hline
\end{tabular}

${ }^{\text {a }}$ Pearson's correlation coefficient ( $p$-value).

${ }^{\mathrm{b}}$ Percent of respondents who responded affirmatively to "Generally speaking, would you say that most people can be trusted or that you can't be too careful in dealing with people?".

${ }^{c}$ Percent of respondents who responded affirmatively to "Do you think most people would try to take advantage of you if they got a chance, or would they try to be fair?".

${ }^{\mathrm{d}}$ Percent of respondents who responded affirmatively to "Would you say that most of the time people try to be helpful, or are they mostly looking out for themselves?".

${ }^{\text {e}}$ Percent of respondents who belonged to at least one of 14 voluntary civic associations.

significant in each time period but one (1982-1985; $r=$ $-0.29, p=0.11)$. Correlations between aggregate membership measure and mortality outcome were weaker. We found a modest, significant inverse association between aggregate membership and homicide mortality in the overall sample $(r=-0.23, p=0.002)$, but the significant association did not persist when the data were stratified by time period. 

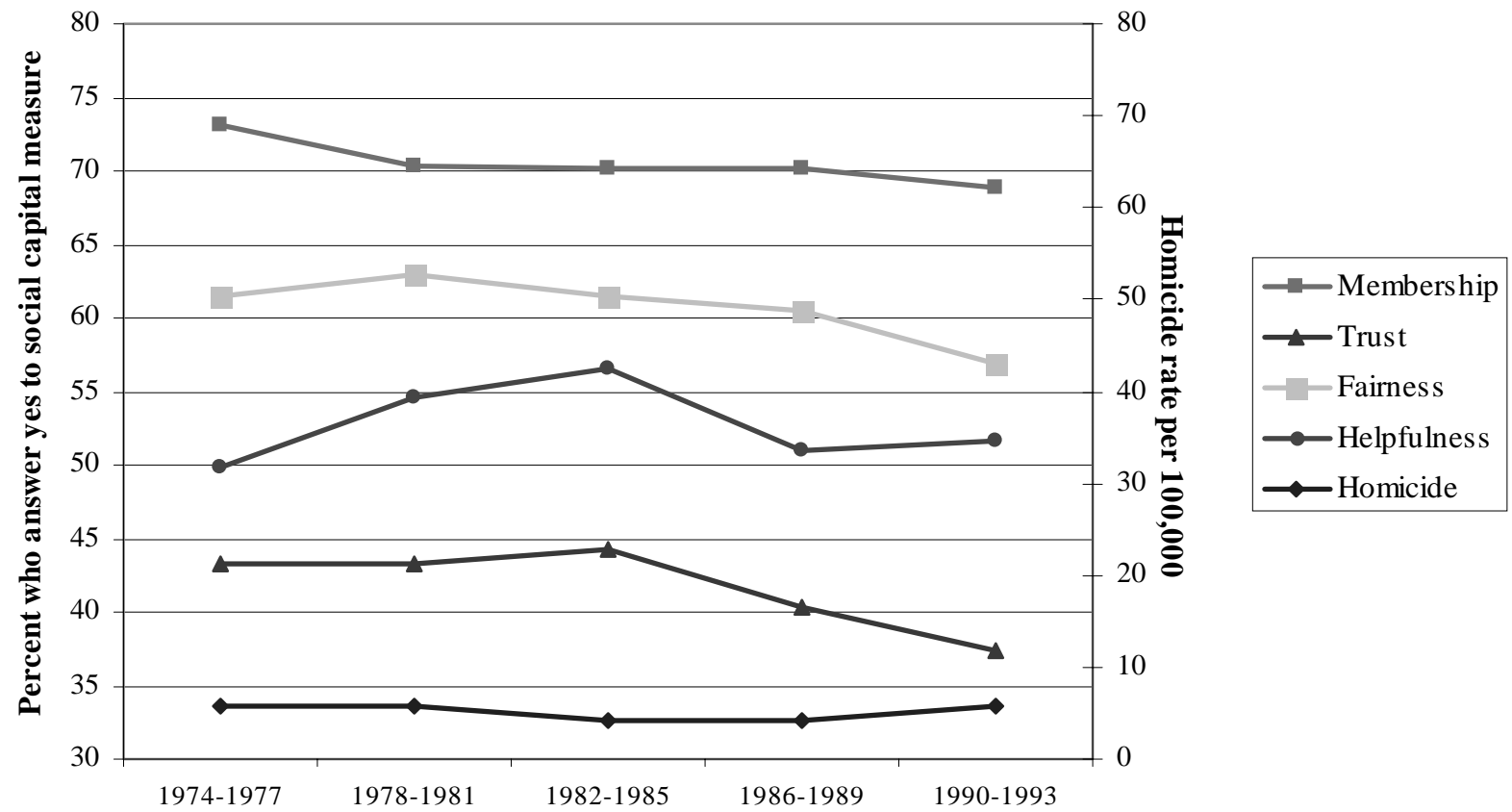

Fig. 2. Homicide and social capital in 32 US states, 1974-1993.

Time trends for perceived trust, aggregate membership, and homicide mortality, 1974-1993.

Time trends in the social capital indicators and in homicide mortality are presented in Fig. 2. We explored the overall variability over time across states and within each state. In general, the social capital measures exhibited limited within state variability across time. Although the intra-state variability was small, the interstate variability was high. Thus, some states had chronically low measures of aggregate membership or measures of perceived trust, whereas others were persistently high.

We examined trends in homicide mortality, stratified by measures of social capital (Fig. 3). At all time periods, mortality from homicide and from all causes was higher among states with lower social capital. In addition, greater amount of mortality rate variability was present within the low perceived trust stratum compared with the high perceived trust stratum.

\section{Ordinary least squares regression, and generalized estimating equation modeling}

Ordinary least squares regression modeling of perceived trust and homicide mortality over time revealed a significant association between perceived trust and homicide mortality both when violence was modeled as dependent variable $(\beta=-0.13,95 \%$ confidence intervals $(\mathrm{CI})=(-0.16,-0.09))$, and when trust was modeled as dependent variable $(\beta=-2.11,95 \%$ $\mathrm{CI}=(-2.66,-1.56))$ in models adjusted for income, region, and urbanization (Table $3 \mathrm{a}$ and $3 \mathrm{~b}$ ). Income and urbanization were significant confounders but region was not. The membership measure was also associated with homicide mortality rates $(\beta=-0.08,95 \%$ $\mathrm{CI} .=(-0.14,-0.02)$ ) in adjusted models (data not shown). We fit generalized estimating equations models (GEE) to account for the correlated nature of the data; a significant association between perceived trust and homicide mortality was present both when violence was modeled as dependent variable $(\beta=-0.13,95 \%$ $\mathrm{CI}=(-0.17,-0.08))$, and when trust was modeled as dependent variable $(\beta=-2.11, \quad 95 \%$ $\mathrm{CI}=(-2.94,-1.38))$ in models adjusted for income, region and urbanization (Fig. 3a, b, Tables 3a, b). Income and urbanization were significant confounders but region was not. Models adjusted for income, region, and urbanization are presented to maintain consistency with some of the dominant theories in violence etiology discussed earlier.

\section{Change models and transitional logistic models}

In the change models, change in homicide rates did not predict change in perceived trust or membership (Table 3a). Similarly, changes in social capital variables did not predict changes in homicide rates (Table $3 \mathrm{~b}$ ). In 


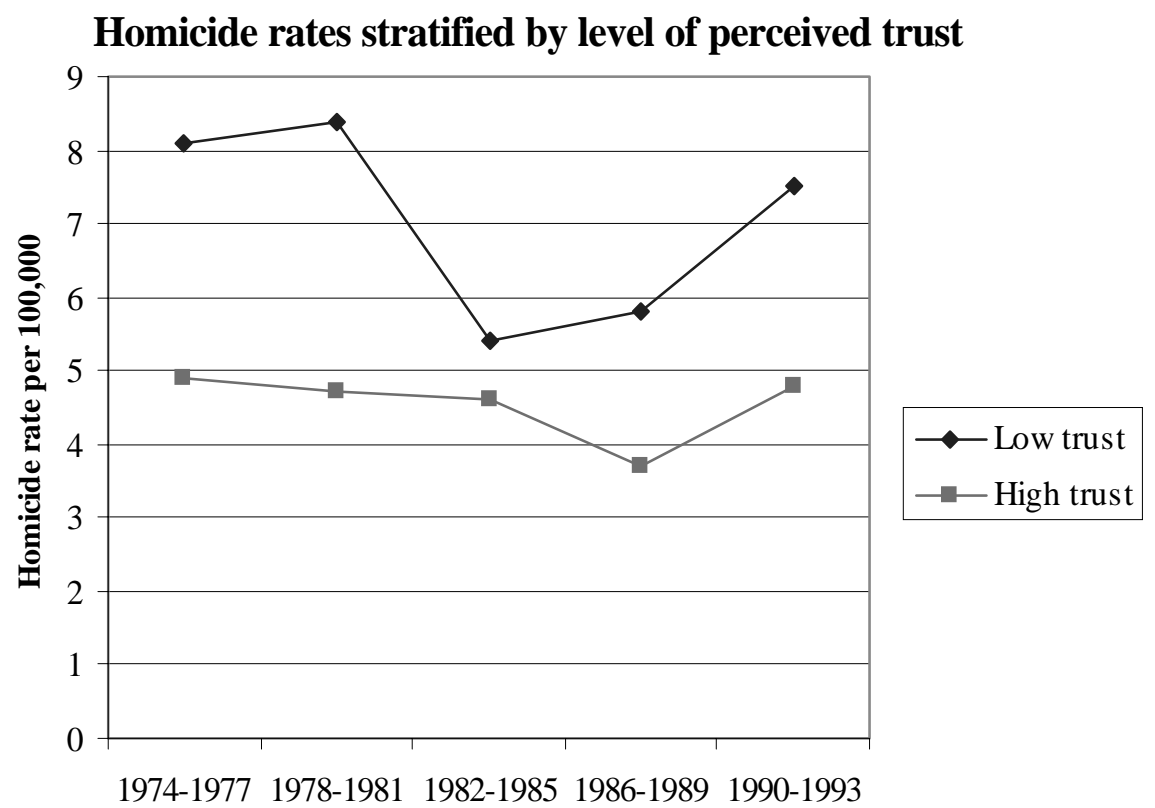

\section{Homicide rates stratified by level of membership}

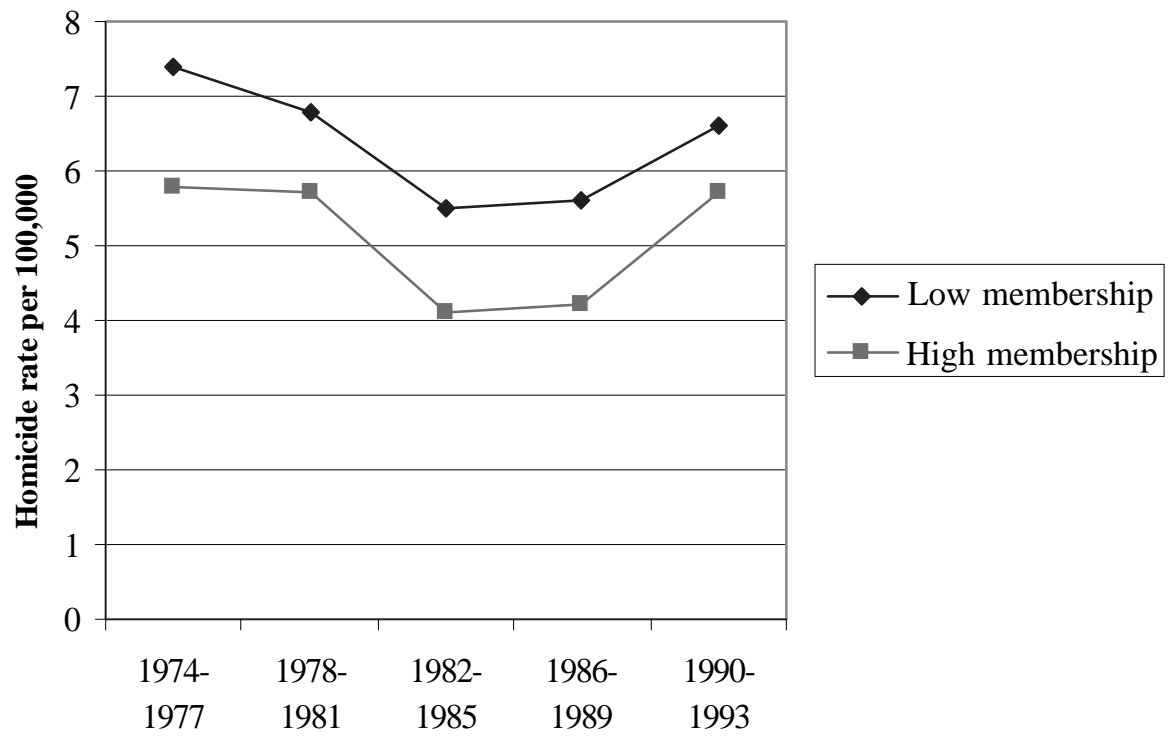

Fig. 3. Homicide mortality stratified by mean levels of trust and membership across 32 US states, 1974-1993.

the transitional logistic models, the homicide rate at time $t-1$ was a strong predictor of the homicide rate at time $t(\beta=6.17,95 \% \mathrm{CI}=(4.16,8.19))$ and trust at time $t$ was not a significant predictor of homicide rate $(\beta=-0.68$, $95 \% \mathrm{CI}=(-2.27,0.92))$ (Table 3a). In models with trust as dependent variable, although trust at $t-1$ was a strong predictor of trust at time $t(\beta=1.76,95 \%$ $\mathrm{CI}=(0.94,2.58))$, homicide rates at time $t$ were also significant predictors of trust at time $t(\beta=-1.78,95 \%$ $\mathrm{CI}=(-2.66,-0.96))($ Table $3 \mathrm{~b})$.

Markov transitional state analysis

The Markov transitional probability matrices for each of the four transitions as well as an aggregate matrix are presented in Table 4. Analysis of Markov transitional 
Table 3

\begin{tabular}{llll}
\hline Model & $\beta$ & Standard error & $p$-value \\
\hline
\end{tabular}

(a) Regression model parameters describing the association between perceived trust and homicide rates in 32 US states, homicide as dependent variable; 1974-1993

Generalized estimating equations

Simple model

Trust $^{\mathrm{a}}$

Adjusted model ${ }^{\mathrm{b}}$

Trust $^{\mathrm{a}}$

$$
-0.131
$$

$-0.126$

Change models

Simple model

Change in trust ${ }^{\mathrm{c}}$

Adjusted model $^{\mathrm{b}}$

Change in trust ${ }^{\mathrm{c}}$

$\begin{array}{ll}-0.066 & 0.076\end{array}$

$-0.062$

Transitional model

Trust at time $t^{\mathrm{d}}$

Homicide at time $t-1^{\mathrm{d}}$
0.022

$<0.0001$

0.076

0.418
0.812

1.03
$<0.0001$

$-0.676$

6.174

$$
-1.983
$$$$
-2.111
$$

$-0.086$

$$
-1.78
$$

0.323

0.374

0.103

0.106

0.420

0.420
$<0.0001$

$<0.0001$

0.390

0.418

0.003

$<0.0001$

\footnotetext{
${ }^{a}$ Models describe the association between a one percentage change in mean trust in a state with a one person per 100,000 change in homicide mortality rate.

${ }^{\mathrm{b}}$ Models adjusted for state mean income, urbanization and region of the US.

${ }^{\mathrm{c}}$ Change in homicide rates between time periods associated with change in percentage trust in a state between time periods.

${ }^{\mathrm{d}}$ Model in the form of Homicide $=\beta_{0}+\beta_{1}$ trust $_{t}+\beta_{2}$ homicide $_{t-1}+\varepsilon$.

${ }^{\mathrm{e}}$ Change in percentage trust in a state between time periods associated with change in homicide mortality rates in a state between time periods.

${ }^{\mathrm{f}}$ Model in the form of Trust $=\beta_{0}+\beta_{1}$ homicide $_{t}+\beta_{2}$ trust $_{t-1}+\varepsilon$.
}

probabilities confirm the modest amount of intra-state variability across time periods in each of the four transition matrices as well as in the aggregate matrix; i.e., at time $t+1$, states were more likely to stay within the same Markov category they occupied at any given time $t$ than to have proceeded to a different Markov category. More revealing was the next most common transition between Markov categories. Under a scenario in which social capital changes led to changes in violence rates, high social capital/high violence states would have been expected to transition to high social capital/low violence states. Conversely, low social capital/low violence states would have been expected to change to low social capital/high violence states. The summary transition probabilities of these two phenomena were 0.16 and 0.05 , respectively. Alternatively, under a process whereby levels of violence affect social capital, high social capital/high violence states might transition 
Table 4

Transitional probability matrices for US state movement between Markov categories ${ }^{\mathrm{a}}$

\begin{tabular}{|c|c|c|c|c|c|c|c|c|c|}
\hline & 1 & 2 & 3 & 4 & & 1 & 2 & 3 & 4 \\
\hline & \multicolumn{5}{|c|}{ Transition probabilities time $1-2^{\mathrm{b}}$} & \multicolumn{4}{|c|}{ Transition probabilities time $2-3^{\mathrm{b}}$} \\
\hline 1 & 0.6 & 0.2 & 0.2 & 0.0 & 1 & 0.3 & 0.3 & 0.3 & 0.1 \\
\hline 2 & 0.0 & 0.9 & 0.0 & 0.1 & 2 & 0.0 & 0.8 & 0.0 & 0.2 \\
\hline 3 & 0.1 & 0.1 & 0.8 & 0.0 & 3 & 0.3 & 0.1 & 0.5 & 0.1 \\
\hline 4 & 0.0 & 1.0 & 0.0 & 0.0 & 4 & 0.0 & 0.0 & 0.0 & 1.0 \\
\hline & \multicolumn{5}{|c|}{ Transition probabilities time $3-4^{\mathrm{b}}$} & \multicolumn{4}{|c|}{ Transition probabilities time $4-5^{\mathrm{b}}$} \\
\hline 1 & 0.4 & 0.0 & 0.6 & 0.0 & 1 & 0.7 & 0.0 & 0.3 & 0.0 \\
\hline 2 & 0.0 & 0.6 & 0.1 & 0.3 & 2 & 0.1 & 0.3 & 0.1 & 0.5 \\
\hline 3 & 0.0 & 0.0 & 1.0 & 0.0 & 3 & 0.0 & 0.0 & 1.0 & 0.0 \\
\hline 4 & 0.1 & 0.3 & 0.0 & 0.6 & 4 & 0.0 & 0.4 & 0.1 & 0.5 \\
\hline & \multicolumn{4}{|c|}{ Overall transition probability matrix } & & & & & \\
\hline 1 & 0.48 & 0.16 & 0.32 & 0.04 & & & & & \\
\hline 2 & 0.02 & 0.65 & 0.05 & 0.28 & & & & & \\
\hline 3 & 0.10 & 0.05 & 0.82 & 0.03 & & & & & \\
\hline 4 & 0.05 & 0.32 & 0.05 & 0.58 & & & & & \\
\hline
\end{tabular}

${ }^{a}$ Markov categories: (1) High Social Capital/High Violence, (2) High Social Capital/Low Violence, (3) Low Social/Capital High Violence, and (4) Low Social Capital/Low Violence. Percent responding: "Most people can be trusted" used as measure of Social Capital.

${ }^{\mathrm{b}}$ Time periods were: Time 1=1974-1977; Time 2=1978-1981; Time 3=1982-1985; Time 4=1986-1989; and Time 5=1990-1993.

to low social capital/high violence states, and low social capital/low violence states might change to high social capital/low violence states. The overall transition probabilities for these two developments were considerably greater, at 0.32 and 0.32 , respectively. Thus, a US state was far more likely to transition from a high violence category to a low social capital category or from a low violence category to a high social capital category than from either a low social capital category to a high violence category or a high social capital category to a low violence category.

\section{Discussion}

Measures of perceived trust and voluntary association membership have been used to measure social capital (Lochner, Kawachi, \& Kennedy, 1999). We adopted different analytic techniques to those previously employed to better characterize the relationship between these indicators and violence. Our pooled sample of US states confirmed the negative cross-sectional correlations between measures of trust and homicide mortality previously documented in smaller samples of state-level data. These correlations were consistent over the five time-periods examined. US states with low levels of perceived trust had consistently higher levels of homicide mortality than did states with high levels of perceived trust. The association between aggregate membership and homicide mortality was not consistent over all time periods.

Generalized linear modeling confirmed this inverse association between social capital measures and homicide mortality. This relationship remained robust when controlling for degree of urbanization, region of the country, and relative income across states and when accounting for correlation of results within states over time. Income and urbanization were important confounders of the relation between perceived trust and homicide mortality. Exploring the dynamic relation between social capital and violence, we observed that in the transitional models the association between social capital measures and homicide mortality loses significance when we controlled for the previous time interval's homicide mortality rate.

Markov transitional model analysis provides some insight into the complexities suggested by the linear models. US states are more likely to stay at a similar level of homicide mortality or of perceived trust over time than they are to change levels between either of these two measures. Of interest are the transitions that US states do make and their respective probabilities. US states with high levels of homicide mortality are more likely to erode social capital than states with high levels of perceived trust are to experience decline in their homicide mortality. Thus, it appears that, dynamically, when US states do change, violence in communities is more likely to impact on contextual social factors than the converse. 
Previous cross-sectional analyses that have demonstrated the relationship between social capital and mortality suffered from small sample size limited by the number of US states. We overcame some, but not all, of this difficulty by pooling data across five timeperiods. We observed that the relations documented in previous studies are valid with a larger pooled sample size. Our analysis is limited by its reliance on the GSS as the primary source of social capital information. The GSS provides nationally and regionally representative data. Although we weighted responses to the GSS to obtain representative samples at a state level, residual non-differential misclassification remains a potential problem. The GSS also samples English speakers who own a telephone, thus introducing potential systematic sampling bias. General comments on validity and reproducibility of the GSS are documented elsewhere (Brehm \& Rahn, 1997).

Conclusive inference from our analysis is limited by limitations imposed by the data on the analytic techniques. The most significant concern in the limited intra-state variability in covariates over time (Blakely, Kennedy, Glass, \& Kawachi, 2000). While inter-state variations in levels of perceived trust over time are large, intra-state variations are not. Some states (in the South Atlantic and the South-Central regions) have consistently low levels of perceived trust while other states (mid-Atlantic and New England) have consistently high levels. We used the variability in social capital and homicide rates in US states over time to characterize the relation between these two variables. Limited intra-state variability is probably the reason why our change models did not achieve statistical significance. To overcome this limitation we explored the transitions in violence and social capital over time using Markov transitional state analyses. While the latter analysis is qualitative, it does confirm the associations between social capital and violence over time that is suggested by the generalized linear modeling.

A question remains as to whether this level of analysis appropriately measures the features of organizations we seek to describe as social capital. Levels of perceived trust were consistent and robust predictors of mortality outcomes across the period of our analysis, while a measure of association membership was a significant, but weaker, predictor. Putnam's "bowling alone" hypothesis reformulated social capital in the context of association membership in 1995 (Putnam, 1995). We suggest that perceived trust and voluntary association membership might function at different levels and that state-wide estimates of membership do not provide a representative measure of citizen involvement in their communities. Increasingly pervasive mass media saturation can quickly homogenize opinion and sentiment. Voluntary association membership is, however, largely local (Rotolo, 1999). While a survey measure of perceived trust appeared to well describe an underlying contextual social construct associated with homicide mortality, finer hierarchical analyses will be important to characterize the relation between association membership and violence.

Characterizing a relation between social capital and homicide mortality does not prove causation. Regression models assume that variation in the outcome variable can be explained by variation in the independent variables. Though our models confirm that variation in homicide rates can be predicted by variation in social capital, they also suggest that the relation is not unidirectional. We hypothesize that the relationship between these measures is complex and non-linear; that is, it involves feedback loops in which each variable affects and is affected by the other (Levins \& Lopez, 1999). Thus, while social capital engenders informal social control that leads to decreasing violence, high violence rates, accompanied by greater delinquency, may result in growing mistrust among community members and an erosion of social capital.

\section{Conclusions and research direction}

Sociologists and social epidemiologists have described and studied contextual determinants such as social capital, social cohesion, and collective efficacy and their relationship to community violence. We suggest that clarification of the relationships between perceived trust, membership, and homicide mortality adds further insight into this thinking and introduces additional complexity.

While we can predict homicide mortality through use of state-level measures of trust, we observe a significant decrease in trust as homicide rates rise. Income is a potent confounder in these relationships as is degree of urbanization. We postulate that social capital is part of a complex system of interactions between individual and ecologic determinants of health. While it is certainly possible that disinvestment in social capital antecedes increasing homicide rates, we demonstrate suggestions of a feedback dynamic not fully explained by extant models. This complexity must be acknowledged and examined to better describe the impact of social factors on violence.

\section{References}

Blakely, T., Kennedy, B., Glass, R., \& Kawachi, I. (2000). What is the time lag between income inequality and health status? Journal of Epidemiology and Community Health, 54, 318-319.

Brehm, J., \& Rahn, W. (1997). Individual-level evidence for the causes and consequences of social capital. American Journal of Political Science, 41, 999-1023. 
Coleman, J. S. (1990). Foundations of social theory. Cambridge, MA: Harvard University Press.

Cubbin, C., Williams Pickle, L., \& Fingerhut, L. (2000). Social context and geographic patterns of homicide among US black and white males. American Journal of Public Health, 90, 579-587.

Cunradi, C. B., Caetano, R., Clark, C., \& Schafer, J. (2000). Neighborhood poverty as a predictor of intimate partner violence among white, black, and hispanic couples in the United States: A multilevel analysis. Annals of Epidemiology, 10, 297-308.

Dahlberg, L. L., \& Potter, L. B. (2001). Youth violence. Developmental pathways and prevention challenges. American Journal of Preventive Medicine, 20(1S), 3-14.

Diggle, P., Liang, K. Y., \& Zeger, L. (1995). Analysis of longitudinal data. Oxford: Clarendon Press.

Goldstein, P. (1998). Drugs, violence and federal funding: A research odyssey. Substance Use and Misuse, 33(9), 19151936.

Hawe, P., \& Schiell, A. (2000). Social capital and health promotion: A review. Social Science and Medicine, 51, 871885.

Johnson, J. G., Cohen, P., Smailes, E., Kasen, S., Oldham, J. M., Skodol, A. E., \& Brook, J. S. (2000). Adolescent personality disorders associated with violence and criminal behavior during adolescence and early adulthood. American Journal of Psychiatry, 157, 1406-1412.

Kawachi, I. (1999). Social capital and community effects on population and individual health. In N. E. Adler, M. Marmot, B. S. McEwen, \& J. Stewart (Eds.), Socioeconomic status and health in industrial nations: Social, psychological and biological pathways. New York, NY: New York Academy of Sciences.

Kawachi, I., Kennedy, B. P., Lochner, K., \& Prothrow-Stith, D. (1997). Social capital, income inequality and mortality. American Journal of Public Health, 87, 1491-1498.

Kawachi, I., Kennedy, B. P., \& Wilkinson, R. G. (1999). Crime: Social disorganization and relative deprivation. Social Science and Medicine, 48, 719-731.

Kennedy, B. P., Kawachi, I., Prothrow-Stith, D., Lochner, K., \& Gupta, V. (1998). Social capital, income inequality and firearm violent crime. Social Science and Medicine, 47, 7-17.

Klevens, J., Bayón, M. C., \& Sierra, M. (2000). Risk factors and context of men who physically abuse in Bogotá, Colombia. Child Abuse and Neglect, 24(3), 323-332.
Land, K., McCall, P., \& Cohen, L. (1990). Structural covariates of homicide rates: Are there any invariances across time and space? American Journal of Sociology, 95, 922-963.

Levins, R., \& Lopez, C. (1999). Toward an ecosocial view of health. International Journal of Health Services, 29, 261-293.

Lochner, K., Kawachi, I., \& Kennedy, B. P. (1999). Social capital: A guide to its measurement. Health and Place, 5, 259-270.

Morenoff, J. D., \& Sampson, R. J. (1997). Violent crime and the spatial dynamics of neighborhood transition: Chicago, 1970-1990. Social Forces, 76(1), 31-64.

Morgenstern, H. (1995). Ecologic studies in epidemiology: Concepts, principles, and methods. Annual Review of Public Health, 16, 61-81.

Perry, J. C., Lavori, P. W., \& Hoke, L. (1987). A Markov model for predicting levels of psychiatric service use in borderline and antisocial personality disorders and bipolar type II affective disorder. Journal of Psychiatric Research, 21, 215-232.

Putnam, R.D. (1993). The prosperous community. Social capital and economic growth. The American Prospect, Spring, 35-42.

Putnam, R. D. (1995). Bowling alone. America's declining social capital. Journal of Democracy, 6, 65-78.

Quetelet, L. A. J. (1842). A treatise on man and the development of his faculties. Edinburgh: W and R Chambers.

Rotolo, T. (1999,). Trends in Voluntary Association Participation. Nonprofit and Voluntary Sector Quarterly, 28, 199-212.

Sampson, R. J., Raudenbush, S. W., \& Earls, F. (1997). Neighborhoods and violent crime: A multilevel study of collective efficacy. Science, 277, 918-924.

Sampson, R. J., \& Wilson, W. J. (1995). Toward a theory of race, crime, and urban inequality. In J. Hagan, \& R. D. Peterson (Eds.), Crime and inequality. Stanford, CA: Stanford University Press.

Shaw, C. R., \& McKay, H. (1942). Juvenile delinquency and urban areas. Chicago: University of Chicago Press.

Silberman, C. E. (1978). Criminal violence, criminal justice. New York: Random House.

Singh, G. K., Kochanek, K. D., \& MacDorman, M. F. (1996). Advance reports of final mortality statistics, 1994. Monthly Vital Statistics Report, 45(3S), 1-78.

Wolfgang, M. E., \& Ferracutti, F. (1967). The subculture of violence. London: Tavistock. 